\title{
The Visceral Nervous System and its Environments
}

\author{
Giorgio Recordati*
}

\author{
Centro di Fisiologia Clinica ed Ipertensione, Universita' di Milano, Via F. Sforza 35, 20122, Milano, Italy
}

(Received on 2 April 2001, Accepted in revised form on 26 September 2001)

\begin{abstract}
Starting from the observation of the relationships of the biological system with its environments and of the genetically determined neuronal properties of plasticity and rhythmicity, it is possible to propose a new hypothesis about the functional role and organization of the visceral nervous system based on the physical model of the Dissipative Structure by I. Prigogine. The similarily between the visceral nervous system function and this model is supported by the following observations: (1) The visceral nervous system is a complex system, composed of many interacting units, which works away from thermodynamic equilibrium; (2) the functional organization of the nervous system is strongly dependent on internal and external environmental stimuli; (3) it is characterized by the presence of rhythms and periodic behaviors and (4) the internal order of the system is maintained in the continuous interplay between function, structure and fluctuations. On the basis of the present hypothesis, a few general principles can be formulated: (1) the higher brain centers, the fluid matrix and the external world, are the visceral nervous system natural environments; (2) with which it is plastically interfaced as a thermodynamic dissipative structure; (3) its main functional role is to regulate, distribute and maintain ordered exchanges of matter, energy and information between these environments. The present is a general interpretation of the operations of the visceral nervous system as a whole. In the frame of this interpretation the hypotheses so far formulated, including the homeostatic theory, can be viewed as the description of discrete and complementary aspects of the visceral nervous system functions.
\end{abstract}

(C) 2002 Academic Press

\section{Introduction}

The autonomic nervous system (ANS) may synthetically be defined as that part of the nervous system composed of a complex central network, of para-, pre-vertebral and cranial ganglia, of nerve plexuses and of peripheral efferent and afferent neurons, which induces, regulates, coordinates, integrates and perceives visceral functions (Jänig \& Häbler, 1999; Benarroch, 1999; Furness et al., 1999; Landsberg \& Young, 2001). Following a recent proposal (Blessing, 1997), the Langley's term of "autonomic" as well as the

\footnotetext{
*E-mail: giorgio.recordati@unimi.it
}

term "vegetative" (Jänig \& Häbler, 1999) will be avoided in the present paper, and the ANS will be simply termed the visceral nervous system (VNS). WB Cannon, in his analysis of the functional role of the VNS, used Claude Bernard's (1878) concept of the constancy of the "milieu interieur" as a necessary condition for survival and linked it to the functional role of the sympathetic nervous system, with the formulation of the homeostatic theory (HT) (Cannon, 1929; Recordati, 1984). This theory, which has been and is one of the most widely used conceptual reference, assumes that the functional role of the sympathetic nervous system is to maintain the constancy of the fluid matrix, despite continuous threatening 
environmental stimuli (Cannon, 1929, 1939, 1953; Recordati, 1984). On the other hand, WR Hess, who showed for the first time that instinctive behaviors may be elicited by electrical stimulation of discrete regions of the hypothalamus (Hess, 1957; Moruzzi, 1969), proposed to view the functional role of the VNS in the mobilization and utilization of energies to do work (ergotropic function) and in the preservation of internal tissues (trophotropicendophylactic function), functions respectively induced by the sympathetic and parasympathetic divisions of the VNS (Hess, 1957, pp. 35-42, 1981). J. Pick shared Hess's view and described the VNS functional role in terms of the utilization (katabolic) and preservation (anabolic) of bodily energy stores (Pick, 1970, pp. 31-33), in other words in the exchange of energy between the internal and external environments.

In comparison with the wide acceptance of Cannon's hypothesis, those formulated by Hess and Pick, although based on an extensive analysis of the comparative anatomy and physiology of the VNS and on evolutionary considerations received less attention at the time of their original presentation and were seldom used thereafter. The actual wealth of knowledge about the VNS stimulates to proceed further, and to attempt at integrating the general principles about the functional properties of the VNS outlined above into an evolutionary perspective.

For this purpose and starting from the definition of a biological system (BS), the thermodynamic theory by I. Prigogine of the dissipative structure (DS) offers one of the safest moorings (Yates, 1987). This theory was developed with the purpose of giving a physicist's description of the biological order, of the appearance of new ordered structures and of the biological evolution (Nicolis \& Prigogine, 1977; Prigogine, 1978; Prigogine \& Stengers, 1979, 1984). It will be used, therefore, as a model of reference to attempt an interpretation of the origin and evolution of the VNS and to propose a few general principles about the functional role and organization of the VNS. The following two premises are, however, needed to help in understanding the interpretation presented here.
First, the model of the DS, as detailed in the next section, describes how a neuronal network, for example, may be shaped in the course of evolution by environmental forces or stimuli in order to give origin to organized groups of neurons, and their circuitries, with specialized common specific functions. The VNS is composed of many different neuronal groups such as baro- and chemoreceptors, hypothalamic and brainstem centers. All of them, either subserving homeostatic or non-homeostatic functions, taken separately, may be described as discrete DS. All these DS have been assembling in the course of evolution to give rise to the actual structural and functional complexity of the VNS. It should be clear from the beginning that the present proposal, therefore, is not intended to dismiss nor to dispute the HT, but rather to build a general scheme of interpretation of VNS function, inside which the HT will also be included, because even homeostatic structures may be regarded as DS.

Second, in spite of the central and peripheral complexity of the VNS, in the present paper the VNS, for the sake of simplicity, will be considered as a single neuronal network, a single DS. By doing this, the cholinergic, adrenergic and the non-adrenergic non-cholinergic (NANC) outputs (Burnstock, 1986), will be analysed under the aspect of their common functional properties only, such as the ability to utilize energy to do work, the neuronal plasticity, and their dynamic and rhythmic components. In the present paper, no mention will be made, for example, of the different physiological actions of the sympathetic and parasympathetic components of the VNS. Hence, the general principles drawn at the end have been elaborated and should be considered valid for the three main divisions of the VNS: sympathetic, parasympathetic and enteric nervous system as defined by Langley (see Jänig \& Häbler, 1999, p. 4).

Given these premises, the aim of the present work is to attempt the design of a simple and, at the same time, comprehensive conceptual framework for the VNS as a whole inside which all the theories so far formulated may be placed, then providing investigators with a helpful theoretical instrument of reference (Recordati, 1984, 1989, 1990). 


\section{The Biological System and the Dissipative Structure}

A BS may be defined as a thermodynamic open system continuously exchanging matter, energy and information with its environment. These exchanges in turn guarantee the stability and growth of the BS. Because of these characteristics the system is susceptible to evolution, adapting to a changing environment (Prigogine, 1978; Prigogine \& Stengers, 1979; Omodeo, 1983).

The thermodynamic theory for the living organism has been developed by I. Prigogine to give a physicist's description of the biological order and evolution. The appearance of ordered structures in the course of evolution and their maintenance are in principle possible if a flow of negative entropy is supplied to the system, or if the system, to do work, import energy from outside (Prigogine, 1978; Prigogine \& Stengers, 1979). This condition may be valid for a thermodynamic open system composed of many interacting subunits and exchanging matter and energy with its environment. For the appearance of ordered structures additional conditions to be satisfied are, first, that the thermodynamic open system does exist and work away from the thermodynamic equilibrium (see Section 3.1); second, that the functional organization of the system is kept in relation to the environmental forces, such as heat (see Section 3.2) and, third, that nonlinear dynamic relationships occur between the elements of the system. In biological complex structures this last condition is always satisfied, because of the interactions of various and simultaneous chemical reactions and physiological processes the control of which implies highly nonlinear elements (Prigogine \& Stengers, 1979). A very clear and simple description, graphically and mathematically illustrated, of what is meant by a nonlinear function may be found in Denton et al. The rising and falling portion of the classical Frank-Starling relation between cardiac performance and filling volume, which are VNS regulated variables, is an example of a nonlinear system, because at a single value of $y$ two different values of the variable $x$ may correspond (Denton et al., 1990).

In a thermodynamic open system, which works away from equilibrium under the influence of environmental physical forces, Prigogine \& Stengers (1979, pp. 10-11 and p. 81), have remarked that new ordered structures may thus appear. These structures are dissipative structures because they originate in the continuous exchange of matter and energy with the external environment, and utilize as well as dissipate energy to do work. These structures are ordered and the order inside the system is maintained through fluctuations which may be periodic and rhythmic with a strong dependency among structure, function and fluctuations (Section 3.3) (Prigogine, 1978). As the system is driven far away from equilibrium, moreover, a single stationary-state may subdivide to give origin to two possible different states of the system, the phenomenon of branching or bifurcation. This behavior, as it is known, is described by an ad hoc developed mathematical theory, the mathematics of catastrophes, and chaos (Nicolis \& Prigogine, 1977; Prigogine, 1978; Prigogine \& Stengers, 1984; Denton et al., 1990).

In physics, a typical example of a DS is the regular convection cells generated in water brought above a critical temperature by an external source of heat. Intuitive sociobiological examples are the evolution of ecosystems, growth and distribution of populations and the formation of cooperative groups. Biological examples are the glycolytic cycle, protein synthesis and the separation of electrical charges across cellular membranes and amongst the most interesting and possible biological applications related to the present article, are the organization of neuronal, endocrine and immune networks (Nicolis \& Prigogine, 1977, p. 466). In this case, a neuronal network is considered as an open thermodynamic system exchanging matter and energy with the internal and external environments, and composed of many interacting units, the neuronal and glial cells. Under the influence of environmental forces and away from the thermodynamic equilibrium, new structures may appear, such as groups of neurons with shared functional properties, either directed towards maintaining constancy or towards promoting changes. For example, the arterial baroreceptors which emerged in the course of evolution to meet new conditions of terrestrial life, when stimulated cause a reflex decrease of peripheral sympathetic 
activity (Segar, 1997), while the arterial chemoreceptors, when stimulated produce opposite effects (de Burgh Daly, 1997). The possibility exists that centrally located groups of neurons, such as hypothalamic and brainstem centers, were shaped by the complex interactions with the external and internal environments. For these reasons, Prigogine's theory of the DS is one of the main theoretical background for the description of the self-organization of the BS (Yates, 1987; Pattee, 1987).

The concept that the model of the DS may be usefully applied to the study of the VNS and that it may satisfactorily describe the phylogenetic development of the VNS and its present configuration is supported by the observation that the conditions necessary for the existence of a DS are all verifiable for the VNS, namely: (1) The VNS is composed of many interacting, nonlinearly related, units which contribute to keep the visceral apparatus and visceral function away from the thermodynamic equilibrium; (2) the functional organization of the VNS is maintained and is dependent on the action of the internal (higher brain centers and fluid matrix) and external stimuli, or forces, upon the system; (3) the VNS's function shows dynamic, rhythmical and periodic components, with a strong dependency among function, structure and fluctuations. As outlined by the definition of the BS and by the description of the DS given above, these conditions are the system's properties which allow the appearance of new $D S$ and, at the same time, system adaptation and evolution. These conditions will now be discussed in the following sections.

\section{Experimental Evidence for the Proposed View}

\subsection{AWAY FROM EQUILIBRIUM}

Blood volume displacement according to gravity force during standing is usually counterbalanced by increased sympathetic vasoconstrictor activity. When cardiovascular neurons are unable to develop an adequate distribution of pressure gradients inside the cardiovascular system, as during a vasovagal attack, blood volume may move towards equilibrium with the force of gravity and syncope occurs (Recordati, 1999; Mosqueda-Garcia et al., 2000). Additional demonstrations are offered by symptoms occur- ring in peripheral autonomic failure and in all dysautonomic conditions: erectile dysfunction, hypohydrosis and compensatory hyperhydrosis, cardiac dysrythmias, alterations in gastrointestinal and bowel functions, salivary and lacrimal glands, are all indicative of the lack of an adequate function of the VNS and of adequately developed internal gradients (Bannister \& Mathias, 1999).

During normal daylife, the VNS continuously develops and maintains gradients with the outside environment and between different compartments of our internal visceral apparatus: although all these VNS functions are usually seen as homeostatic, by these homeostatic actions the VNS keeps the BS away from thermodynamic equilibrium, away from a condition of equality with the environmental forces and works as a DS. Each behavioral response pattern is characterized by a typical distribution of internal gradients, in such a way that the term "pattern" indicates a coordinated and predictable target organ response to centrally driven activation and inhibition of specific VNS neuronal pools. For example, blood pressure, heart rate and sympathetic nervous system activity are lowest during synchronized sleep, and maximal during arousal, the fight and flight (defence) reaction and strenuous muscle exercise (Zanchetti, 1986; Sommers et al., 1993; Spyer, 1999; Folkow, 2000a). The defence reaction is characterized by vasodilatation of skeletal muscle, heart and brain, vasoconstriction of gastrointestinal, renal and cutaneous vascular beds, and simultaneous lipid and carbohydrate mobilization from nutritional depots (Hilton, 1982; Zanchetti, 1986; Folkow, 2000a). The main limbic-hypothalamic response patterns, such as defence, vigilance, defeat, playing dead and feeding reactions and the diving response, have been recently reviewed (Folkow, 2000a). A similar description may be found for neuronal circuitries involved in thermoregulation (Nagashima et al., 2000). Each behavior may therefore be characterized by different distributions of gradients in the internal environment and different production of gradients with the outside world, in such a way that the VNS functional organization may be viewed as maintained through fluctuations amongst different behavioral patterns. 
In this connection, a symmetry between two extreme conditions is worth mentioning. During sleep, which is a behavioral condition internally oriented and characterized by the prevalence of vagal tone (Malliani, 2000), the system temporarily loses the ability to regulate temperature (Parmeggiani, 1988), i.e. developing adequate gradients with the outside environment. In contrast, during strenuous exercise, which is a behavioral condition externally oriented, characterized by a prevalence of sympathetic tone (Malliani, 2000), the arterial baroreflex operating point shifts to higher pressures and the reflex gain is reduced (Segar, 1997; DiCarlo \& Bishop, 1999), and consequently the ability of the system to regulate blood pressure, that is to maintain adequate gradients with the internal environment, is markedly decreased (Coote et al., 1979; Segar, 1997; Spyer, 1999; DiCarlo \& Bishop, 1999).

For these reasons, the level of activation of the nervous system is usually described as behaviorally and physiologically state-dependent, this term underlining the state-specific neuronal differences and the dynamic properties of the neuronal circuitries (Hobson \& Steriade, 1986; Lydic, 1987). Likewise, the concepts of dynamic regulation and the dynamic specificity of brain centers have been proposed (Koepchen et al., 1986) to indicate that the neural network is not steadily but dynamically connected: for a given input a differentiated output may be recorded during different behavioral conditions (Hobson \& Steriade, 1986; Koepchen et al., 1986). For example, sympathetic pre-ganglionic neurons show distinct phases of activity correlated with the central respiratory drive, as well as reflexly modulated by pulmonary stretch receptors (Spyer, 1999).

\subsection{CONTRIBUTION OF STIMULI TO THE FUNCTIONAL ORGANIZATION OF THE VNS}

When a stimulus induces alterations of a neuron membrane potential, a signal, and therefore a flow of information, is generated, which may influence the activity of another neuron or of a target organ (Kandel, 1979, 2000; Reinagel, 2001). It has been recently shown that the input-output relationship of a sensory neuron depends not only on the stimulus intensity and on the variance (context) of the stimulus, but also on how frequently the stimulus conditions change (Fairhall et al., 2001; Reinagel, 2001). On the basis of the genetic machinery and of the properties of the nervous cells, the functional organization of the VNS is therefore dependent on environmental stimuli. Which is to say that, like for other neuronal networks, the functional expression of the VNS depends on its genetically determined structural characteristics and on the use of this structure.

\subsubsection{Neuronal Plasticity and Trophic Factors}

Plasticity has been defined as the long-lasting changes in neuronal structure and function, such as synapses, axons and neurotransmitter phenotype, that follow environmental perturbations (Le Douarin et al., 1981; Cotman \& Nieto-Sampedro, 1984; Easter et al., 1985; Arenander \& de Vellis, 1989; Pincus et al., 1992). On the basis of a genetic multipotency and of pre-determined plasticity, neurons are very responsive to environmental forces. Plasticity is also the key element in attempting an interpretation of the phylogenetic evolution of the VNS. Pick suggested that in the course of evolution, new functional expressions emerged, together with an increase in the sympathetic component in almost every visceral organ (Burnstock, 1969; Pick, 1970; Nilsson, 1983).

In addition to plasticity, neurons of the VNS have a pre-determined necessity to establish synaptic connections with other neurons or target organs as exemplified by the description of the trophic factors as factors regulating neuronal survival and determining the long-term dependency between neurons and the cells that they innervate (transmitter expression, neurite growth, etc...) (Cowan et al., 1984; Arenander \& de Vellis, 1989; Pincus et al., 1992; Hendry, 1992). While the prototype of these factors is the Nerve Grown Factor, neuropeptides may exert regulatory effects at all stages of neural ontogeny (Pincus et al., 1992).

\subsubsection{The Final Common Pathway}

Extending from Sherrington's concept, Jänig proposed that also in the VNS the last two 
neurons in the pathway to the effector organ may be functionally characterized as the "final common pathway" (Jänig \& McLachlan, 1999). As far as the post-synaptic membrane receptors are concerned, i.e. the connection with the target organ, adrenergic and muscarinic receptors are known to undergo complex dynamics, like denervation and decentralization supersensitivity, desensitization (downregulation) and modulation of the "coupling" of the receptors to their effectors: the number of adrenergic receptors and their sensitivity is dynamically regulated by a variety of circumstances, including diseases and therapeutic interventions (Lefkowitz et al., 1984; Rockman et al., 1997), as well as circadian variations of neurotransmitter release (Vacas et al., 2001).

\subsubsection{Ontogenesis and Development}

It is known that sensory, affective and cultural experiences are responsible for shaping the developing neural circuitry of the brain and that different regions of the brain have different critical periods of development (Kandel, 1979; Henry, 1997; Jessell \& Sanes, 2000; Anand, 2000; Devroede, 2000). From a condition of open loop, the environmental stimuli contribute to loop closure, hence to the establishment of those synaptic connections that are essential for the reflex regulation of visceral functions (Katz \& Shatz, 1996).

The baroreceptor reflex is an example of a well-studied autonomic reflex circuitry modified by continuous environmental influences. The shift of the reflex operating point towards higher pressures and the resetting, either central and peripheral, of the reflex begins during fetal life and continues with postnatal development, maturation and aging (Segar, 1997).

The sympathetic and parasympathetic components are asynchronous in their development. While the baroreceptor reflex seems to be completely organized shortly after birth (Gootman, 1986; Segar, 1997), a longer latency is required for micturition and defecation reflexes to be satisfactorily integrated at the supraspinal level. These pathways maintain an adequate plasticity also in adulthood, as is demonstrated by the partial reorganization of the reflex at the spinal cord level after spinal cord traumatic injury, which allows automatic micturition to occur on activation of unmyelinated C-fiber afferent neurones (Krenz \& Weaver, 1998; de Groat, 1999).

\subsubsection{Conditioning, Sensory Deprivation and Deconditioning}

From studies of operant conditioning in animals, it has been shown that repeated and prolonged stressfull stimuli may induce sympathetic nervous system activation, arterial hypertension and diffuse target organ damage (Henry, 1997). It is stimulating to compare the effects of excessive and inappropriate induction of stress, with the almost opposite condition of sensory deprivation. The neurons of the occipital cortex deprived of their normal visual sensory input, may become responsive to other stimuli, such as, for example, sound as an expression of the plasticity of function (Kandel, 1979; Katz \& Shatz, 1996). To underline the importance of stimuli in the organization of function it is also worth mentioning the well-known observation that normal men under confinement, if isolated from any environmental synchronizer, and totally blind people have freerunning circadian rhythms (Hobson \& Steriade, 1986; Sack et al., 2000). Weightlessness during space flights may also be considered an example of deprivation of the natural constraint of the force of gravity on the organism as a whole. The orthostatic intolerance (Buckey et al., 1996; Hughson \& Bondar, 1999; Ertl et al., 2000), together with bone demineralization and anemia which may ensue, may also be interpreted as an unmasking of the plasticity of function consequent upon the removal of an environmental constraint. Because of the well-developed plastic properties of the bulbar reticular formation (Hobson \& Steriade, 1986), a chronic peripheral sensory denervation, for example of arterial baroand chemoreceptors, may be followed by a central reorganization of reflex pathways subserving the respiratory and the cardiovascular systems (Segar, 1997; de Burgh Daly, 1997; Mancia et al., 1999).

\subsubsection{Higher Level of Integration, Stress, Risk Factors and Cardiovascular Diseases}

The complex patterns of response to environmental "social" stimuli originating at a 
limbic-hypothalamic level (defence, defeat, and feeding reactions, diving response, etc.) are classified on the basis of their cardiovascular reactions (Jänig \& Häbler, 1999; Spyer, 1999; Folkow, $2000 \mathrm{a}, \mathrm{b})$. In this case, as in the case of emotions, the central nervous system is considered as the source of stimuli initiating VNS complex reactions, such as cholinergic muscle vasodilatation in the cat in the preparation of motion (Ellison \& Zanchetti, 1971, 1973; Folkow, 2000a). Similar considerations may apply to disorders that some authors have interpreted as "civilization disorders", such as primary hypertension and the metabolic syndrome (Henry, 1997; Landsberg, 1999; Folkow, 2000a, b). This syndrome, which is also characterized by a diffuse and still unspecified activation of the sympathetic nervous system and by hypertension, is a consistent risk factor for cardiovascular diseases and may be engendered in pre-disposed individuals by a diet rich in saturated fat, alcohol and smoking. The same considerations apply to stressful conditions (Henry, 1997; Folkow, 2000a, b). In this case, however, in addition to genetically pre-disposing factors, the ontogenetic history of the individual, an inadequate affective environment and infant-mother relationship, may also acquire a relevant significance (Kandel, 1979; Henry, 1997). What is worth emphasizing in this context is that these kinds of stimuli need to be active for a prolonged period of time thus giving rise to the possibility that not only a neuroendocrine derangement occurs, but that new functional elements also become established such as developmental changes in the expression of angiotensin II receptors, receptor affinity, and coupling of second messenger systems within central regions involved in the regulation of cardiovascular functions (Segar, 1997).

In conclusion, the stimuli from the outside and inside environments may act upon the VNS at every level of integration of function to maintain the functional organization of the VNS. In other words and along an evolutionary perspective, it may be said that the genetically determined structure develops ontogenetically, becomes more differentiated with increasing complexity of the maintenance of functional structure specificity, and thus becomes more and more dependent on environmental stimuli.

\subsection{RHYTHMS AND PERIODIC BEHAVIORS}

The DS are characterized by a coherent behavior at a supramolecular level, which may give rise to repetitive, oscillatory and rhythmical behaviors (Prigogine, 1978). Rhythms are also inherited properties of biological systems in general and of the VNS in particular. They originate from the interaction with the external environment (entrainment) and are related to day-night (circadian) and seasonal cycles, from the internal environment, and are related to rhythmic activity of visceral organs such as heart and lungs, and of sensory receptors, such as baro and cardiopulmonary receptors, and from endogenous oscillations of central neuronal networks (Hobson \& Steriade, 1986; Lydic, 1989; Gebber et al., 1996; Malliani, 2000).

Since the first recording made by Adrian and Bronk, efferent sympathetic nerve activity is known to be bursting with cardiac and respiratory rhythmicity (McAllen \& Malpas, 1997; Jänig \& Häbler, 1999; Malliani, 2000). Two principal fast rhythms have been described in sympathetic activity, blood pressure and heart rate: one at $10 \mathrm{~Hz}$ and the other at $2-6 \mathrm{~Hz}$. This rhythmical activity has been extensively studied to interpret the influence of efferent sympathetic or vagal tone to the target organs (Lydic, 1989; Gebber et al., 1996; Malliani, 2000).

In pathophysiological states, while the nonlinear terms inside the system may become dominant, bifurcations may appear and the regular periodic behavior is lost: biological phenomena, such as heart rate, may thus become chaotic. Bifurcation mathematics and the chaos theory (see Section 2) have already been applied to verify if complex biological events, such as cardiac arrhythmias and heart failure, can be understood and predicted (Prigogine, 1978; Prigogine \& Stengers, 1984; Denton et al., 1990; Lombardi, 2000).

The presence of rhythms and periodic behaviors and the alteration of different behavioral states such as sleep and arousal, indicate that the internal order of the VNS is maintained through fluctuations and that, as for the DS, a strong relation exists among function, structure and fluctuations. 


\section{Some General Principles about the VNS Functional Role}

Starting from the definition of a BS and taking the DS as an acceptable model of reference, the following generalization about the functional role of the VNS as a whole can be tentatively suggested.

(1) In all vertebrates, the VNS has been considered a complex system under the control of higher brain centers, the internal and the external environments (Jänig, 1988; Jänig \& Habler, 1999; Folkow, 2000b). The stimuli from the internal compartment may originate either from the visceral apparatus as visceral sensory information (Malliani et al., 1973; Recordati et al., 1976, 1980; Furness et al., 1999), from humoral influences (hormones from endocrine organs, gastrointestinal tract, cytokines, etc.) and from higher brain centers as emotional and stressful stimuli, socio-cultural and cognitive experiences (Henry, 1997; Folkow, 2000a, b). Stimuli arising from the external environment are transduced and conveyed by sensory and somatomotor systems to several areas of the nervous system, which give rise to a central representation of the outside world and may elicit somato-visceral reflexes (Sato et al., 1997). The VNS acts as an interface (Jänig, 1988; Jänig \& Häbler, 1999) and transduces all the stimuli, chemicophysical, neurohumoral, emotional, etc., arising from these different fields into biological work. Therefore, the VNS behaves and works like a DS interfaced between higher brain centers, internal and external environments. For human beings, the mental reality, the state of bodily internal neurohumoral and visceral conditions and the external world are the VNS natural environments.

(2) Starting from the definition of the BS and taking the DS as a model of reference, the type of work that the VNS does, may be described as that of regulating and maintaining exchanges of matter, energy and information with its environments and of generating and distributing gradients in the internal environment, the visceral apparatus, along coordinated pattern. The terms matter, energy and information include all possible stimuli acting on this interface and all possible actions induced by it.
(3) As a consequence of the inherited plastic neuronal properties, internal as well external stimuli contribute in shaping the functional structure and organization of the VNS. This may be described as a relationship of reciprocal, circular, causality (for a discussion of the biological causality see Yates, 1980): what the system is called upon to regulate, i.e. the exchanges of matter, energy and information, is what in turn influences its structure and function: the VNS is a plastic interface.

This is a basic concept for our understanding of phylogenetic evolution of the VNS. In any case, time is an important variable to be considered. It has been shown that a stimulus active at the beginning of life may manifest its consequences many years later (Anand, 2000; Devroede, 2000). Hence, this reciprocal causal relationship may also be true on an extended time base.

As a conclusion, the VNS may be described as a nervous DS, plastically interfaced between mind, body and external world, to regulate and maintain ordered exchanges of matter, energy and information within and among its environments.

\section{Perspectives}

The hypothesis presented here is a reproposal and development of the Hess's and Pick's theories on the functional role of the VNS (Hess, 1957; Pick, 1970) and a preliminary attempt at describing what caused the VNS to be what it actually is. It should be noted that this thermodynamic hypothesis does not look at the environmental stimuli as threatening the internal stability of the BS, as the HT does, but rather it presents the relationships between the BS and its environments and the responses to stimuli as naturally occurring events, which contribute to the functional organization and expression, adaptation and evolution of the VNS. It is proposed, therefore, that this approach should be used as a first line of reasoning to evaluate the functional role of the VNS.

In this context the HT may come into play, at a lower level of functional organization only, as the description of that group of physiological functions which are organized as negative 
feedback mechanisms and which are directed to preserve the constancy of the internal variables. Homeostasis is, therefore, a relative concept and it depends from where one looks at it in the frame of the functional hierarchy. As stated by von Bertalannfy: "The dynamic aspect of the problem is, therefore, the broadest one, because starting from the general law of systems and introducing at purpose limitations, it is always possible to reach mechanical functions, while it is impossible to go in the opposite direction." (translated from the Italian Edition, von Bertalannfy, 1971).

We know, furthermore, that in the course of evolution, functions, characterized by a positive interaction between stimulus and response have also emerged, such as the relation between sympathetic activity and energy balance (Young \& Landsberg, 1977; Szekely, 2000), the somatosympathetic reflexes (Sato et al., 1997), and viscero-visceral spinal sympathetic reflexes (Beacham \& Perl, 1964; Malliani, 2000) and the positive feedback interactions between angiotensin and the sympathetic nervous system (Zimmerman et al., 1984; Zanchetti, 1986; Recordati et al., 2000). Different structures with heterogenous functional meanings may therefore coexist. Hence, starting from the hypothesis of the DS as a model for the VNS origin and evolution, the thermodynamic hypothesis sets the general framework describing the functional role of the VNS as a whole and all theories so far described may fit this comprehensive framework as complementary, not mutually exclusive, components and as descriptive aspects of the integrated functions.

A final consideration concerns pathophysiology and disease. Given that risk factors and stress are part of our daylife, repetition of noxious stimuli may contribute in producing new organizations or reorganizations of the functional properties of the system with pathological outcomes (Cannon, 1953; Recordati, 1990; Rockman et al., 1997; Henry, 1997; Folkow, 2000b). As is well known in several clinical settings, if, under appropriate therapy, stimuli cease and lifestyle changes, the VNS and the innervated target organs may recover their normal functional role.

We are dealing with a peculiar, very plastic system, whose structure and function may be altered in relation to environmental perturbations: even a stable function, like the baroreceptor-mediated reflex regulation of circulation may lose its stability under particular environmental conditions, such as the virtual absence of the force of gravity. On the other hand, under the influence of repeated and inappropriate stimulations, less stable and more weakly organized structures, like the spinal sympathetic outflow may reorganize and stabilize themselves (Jänig \& McLachlan, 1999; Ourednik et al., 2001). Both the loss of stability and the acquisition of an improper function may contribute to the appearance of pathophysiological states and diseases.

The several critical reviews and the helpful constructive comments by Prof. A. Zanchetti, University of Milan, and Prof. E. R. Perl, University of North Carolina at Chapel Hill, are gratefully acknowledged.

\section{REFERENCES}

ANAND, K. J. S. (2000). Effects of perinatal pain and stress. In: The Biological Basis for Mind Body Interactions, Progress in Brain Research. (Mayer, E. A. \& Saper, C. B., eds), Vol. 122, pp. 117-129. Amsterdam: Elsevier.

Arenander, A. T. \& DE Vellis, J. (1989). Development of the nervous system. In: Basic Neurochemistry (Siegel, G. J., Agranoff, B. W., Albers, R. W. \& Molinoff, P. B., eds), chapter 25, pp. 479-506. New York: Raven Press.

BANNister, R. \& MATHIAS, C. J. (1999). Clinical features and investigation of the primary autonomic failure syndromes. In: Autonomic Failure (Bannister, R. \& Mathias, C. J., eds), 4th Edn. Oxford: Oxford University Press.

BEACHAM, W. S. \& PERL, E. R. (1964). Background and reflex discharge of sympathetic preganglionic neurones in the spinal cat. J. Physiol. 172, 400-416.

BENARROCH, E. E. (1999). Functional anatomy of the central autonomic nervous system. In: Handbook of Clinical neurology, 74: the Autonomic Nervous System. Part I. Normal Functions (Appenzeller, O., ed.), Chapter 2, pp. 53-86. Amsterdam: Elsevier.

BERnARD, C. (1878). Lecons sur les phenomenes de la vie communs aux animaux et aux vegetaux. Deuxieme Lecon. Le trois formes de la vie. Sect. III Vie constante ou libre, pp. 111-124. Paris: J.-B. Bailliere et fills.

BLESSING, W. W. (1997). Inadequate frameworks for understanding bodily homeostasis. Trends Neurosci. 20, 235-239.

Buckey, S. C., Lane, L. D., Levine, B. D., Watenpaugh, D. E., Wright, S. J., Moore, W. E., Gaffney, F. A. \& BlOMQVIST, C. G. (1996). Orthostatic intolerance after spaceflight. Am. J. Physiol. 81, 7-18.

BURNSTOCK, G. (1969). Evolution of the autonomic innervation of visceral and cardiovascular systems in vertebrates. Pharmacol. Rev. 21, 247-324.

BURnstock, G. (1986). The changing face of autonomic neurotransmission. Acta Physiol. Scand. 126, 67-91. 
CANnON, W. B. (1929). Organization for physiological homeostasis. Physiol. Rev. 9, 399-431.

CAnnon, W. B. (1939). The Wisdom of the Body, 2nd Edn, 333pp. New York: W. W. Norton.

CAnnon, W. B. (1953). Bodily Changes in Pain, Hunger, Fear and Rage, 2nd Edn, 404pp. Boston: C. T. Brandfort.

Coote, J. H., Hilton, S. M. \& Perez-Gonzalez, J. F. (1979). Inhibition of the baroreceptor reflex on stimulation in the brain stem defence center. J. Physiol. 288, 549-560.

Cotman, C. W. \& Nieto-Sampedro, M. (1984). Cell biology of synaptic plasticity. Science 225, 1287-1294.

Cowan, W. M., Fawcett, J. W., O’Learly, D. D. M. \& STANFIELD, B. B. (1984). Regressive events in neurogenesis. Science 225, 1258-1265.

de Burgh Daly, M. (1997). Peripheral Arterial Chemoreceptors and Respiratory-Cardiovascular Integration. Monograph of the Physiological Society no. 46. Oxford: Oxford Medical Publications.

de Groat, W. C. (1999). Neural control of the urinary bladder and sexual organs. In: Autonomic Failure (Mathias, C. J. \& Bannister, R., eds), 4th Edn, Chapter 19, pp. 151-165. Oxford: Oxford University Press.

Denton, T. A., Diamond, G. A., Helfant, R. H., Khan, S. \& Karagueuzian, H. (1990). Fascinating rhythm: a primer on chaos theory and its application to cardiology. Am. Heart J. 120, 1419-1440.

Devroede, G. (2000). Early life abuses in the past history of patients with gastrointestinal tract and pelvic floor dysfunctions. In: The Biological Basis for Mind Body Interactions. Progress in Brain Research (Mayer, E. A. \& Saper, C. B., eds), Vol. 122, pp. 131-155. Amsterdam: Elsevier.

DiCARlo, S. E. \& Bishop, V. S. (1999). Exercise and the autonomic nervous system. In: Handbook of Clinical Neurology, 74: the Autonomic Nervous System. Part I. Normal Functions (Appenzeller, O., ed.), Chapter 8, pp. 245-272. Amsterdam: Elsevier.

Easter, S. S., Purves, D., Rakic, P. \& Spitzer, N. C. (1985). The changing view of neural specificity. Science 230, 507-511.

Ellison, G. D. \& Zanchetti, A. (1971). Specific appearance of sympathetic cholinergic vasodilatation in muscles during conditioned movements. Nature 232, 124-125.

Ellison, G. D. \& ZANChetTi, A. (1973). Diffuse and specific activation of sympathetic cholinergic fibers of the cat. $\mathrm{Am}$. J. Physiol. 225, 142-149.

Ertl, A. C., Diedrich, A. \& Biaggioni, I. (2000). Baroreflex dysfunction induced by microgravity: potential relevance of postflight orthostatic intolerance. Clin. Aut. Res. 10, 269-277.

Fairhall, A. L., Lewen, G. D., Bialek, W. \& DE Reyter VAN STEVENINCK, R. R. (2001). Efficiency and ambiguity in an adaptive neural code. Nature 412, 787-792.

FolKow, B. (2000a). Perspectives on the integrative functions of the 'sympathoadrenomedullary system'. Auton. Neurosci. 83, 101-115.

FOLKOw, B. (2000b). Man's two environments and disorders of civilization: aspects on prevention. Blood Press. 9, 182-191.

Furness, J. B., KunZe, W. A. \& Clerc, N. (1999). Nutrient tasting and signalling mechanisms in the gut II. The intestine as a sensory organ: neural, endocrine, and immune responses. Am. J. Physiol. 277, G922-G928.
Gebber, G. L., Zhong, S. \& Paitel, Y. (1996). Bispectral analysis of complex patterns of sympathetic nerve discharge. Am. J. Physiol. 271, R1173-R1185.

Gootman, P. M. (1986). Development of central autonomic regulation of cardiovascular function. In: Developmental Neurobiology of the Autonomic Nervous System (Gootman, P. M. \& Clifton, N. J., eds), pp. 279-325. Clifton: Humana Press.

HENDRY, I. A. (1992). Responses of autonomic neurones to target deprivation: axotomy and regeneration. In: Development, Regeneration and Plasticity of the Autonomic Nervous System (Hendry, I. A. \& Hill, C. E., eds), pp. 415-462. Switzerland: Harwood Academic Publishers.

HENRY, J. P. (1997). Psychological and physiological responses to stress: the right hemisphere and the hypothalamo-pituitary-adrenal axis, an inquiry into problems of human bonding. Acta. Physiol. Scand. 640 (Suppl.), 10-25.

Hess, W. R. (1957). The Functional Organization of the Diencephalon. New York: Grune \& Stratton.

Hess, W. R. (1981). Sleep. In: Biological Order and Brain Organization. Selected Works of W. Hess (Akert, K., ed.), pp. 115-129. Berlin: Springer-Verlag.

Hilton, S. M. (1982). The defense-arousal system and its relevance for circulatory and respiratory control. J. Exp. Biol. 100, 159-174.

Hobson, J. A. \& Steriade, M. (1986). Neuronal basis of behavioral state control. In: The Nervous System. Handbook of Physiology, (Mountcastle, V. B., Bloom, F. E. \& Geiger, S. R., eds), Vol. IV, Section 1, pp. 701-823. Baltimore: American Physiological Society.

Hughson, R. L. \& Bondar, R. L. (1999). Autonomic nervous system function in space. In: Handbook of Clinical Neurology, 74: the Autonomic Nervous System. Part I. Normal Functions (Appenzeller, O., ed.), Chapter 9, pp. 273-305. Amsterdam: Elsevier.

JÄNIG, W. (1988). The function of the autonomic nervous system as interface between body and environment. Old and new concepts: WB Cannon and WR Hess revisited. In: Neurobiological Approaches to Human Disease (Hellhammer, D., Florin, J. \& Winer, H., eds), pp. 143-173. Berna: Hans Huber Publisher.

JÄNIG, W. \& HABLER, H.-J. (1999). Organization of the autonomic nervous system: structure and function. In: Handbook of Clinical Neurology, 74: the Autonomic Nervous System. Part I. Normal Functions (Appenzeller, O., ed.), Chapter 1, pp. 1-52. Amsterdam: Elsevier.

JÄNIG, W. \& MCLACHLAN, E. M. (1999). Neurobiology of the autonomic nervous system. In: Autonomic Failure (Mathias, C. J. \& Bannister, R., eds), Chapter 1, pp. 3-15. Oxford: Oxford University Press.

Jessell, T. M. \& SANES, J. R. (2000). The induction and patterning of the nervous system. In: Principles of Neural Science (Kandel, E. R., Schwartz, J. H. \& Jessell, T. M., eds), Chapter 52, pp. 1019-1040. New York: McGraw-Hill. KANDEL, E. R. (1979). Psychotherapy and the single synapse. The impact of psychiatric thought on neurobiological research. N. Engl. J. Med. 301, 1028-1037.

KANDEL, E. R. (2000). Nerve cells and behavior. In: Principles of Neural Science (Kandel, E. R., Schwartz, J. H. \& Jessell, T. M., eds), Chapter 2, pp. 19-35. New York: McGraw-Hill.

Katz, L. C. \& Shatz, C. J. (1996). Synaptic activity and the construction of cortical circuits. Science 274, 1133-1138. 
Koepchen, H. P., Abel, H.-H. \& KlÜßEndorf, D. (1986). Central cardiorespiratory organization. In: Neural Mechanisms and Cardiovascular Disease. Fidia Research Series (Lown, B., Malliani, A. \& Prosdocimi, M., eds), Vol. 5, pp. 119-131. Padova: Liviana Press.

KRENZ, N. R. \& WEAVER, L. C. (1998). Sprouting of primary afferent fibers after spinal cord transection in the rat. Neuroscience 85, 443-458.

LANDSBERG, L. (1999). Role of the sympathetic adrenal system in the pathogenesis of the insulin resistance syndrome. Ann. NY Acad. Sci. 892, 84-90.

LANDSBERG, L. \& Young, J. B. (2001). Physiology and pharmacology of the autonomic nervous system. In: Harrison's, Principles of Internal Medicine (Braunwald, E., Fauci, A. S., Kasper, D. L., Hauser, S. L., Longo, D. L. \& Jameson, J. L., eds), pp. 438-450. New York: McGraw-Hill.

Le Douarin, N. M., Smith, J. \& Le Lievre, C. S. (1981). From the neural crest to the ganglia of the peripheral nervous system. Am. J. Physiol. 43, 653-671.

Lefkowitz, R. J., Caron, M. G. \& Stiles, G. L. (1984). Mechanisms of membrane-receptor regulation. N. Engl. J. Med. 310, 1570-1579.

LOMBARDI, F. (2000). Chaos theory, heart rate variability, and arrhythmic mortality. Circulation 101, 8-10.

LYDIC, R. (1987). State-dependent aspects of regulatory physiology. Faseb J. 1, 6-15.

LYDIC, R. (1989). Central pattern-generating neurons and the search for general principles. Faseb J. 3, 2457-2468.

Malliani, A. (2000). Principles of Cardiovascular Neural Regulation in Health and Disease. Boston: Kluwer Academic Publishers.

Malliani, A., Recordati, G. \& Schwartz, P. J. (1973). Nervous activity of afferent cardiac sympathetic fibres with atrial and ventricular endings. J. Physiol. 229, 457-469.

Mancia, G., Parati, G., Castiglioni, P. \& Di Rienzo, M. (1999). Effect of sinoaortic denervation on frequency-domain estimates of baroreflex sensitivity in conscious cats. Am. J. Physiol. 276, H1987-H1993.

MCAllen, R. M. \& MALPAS, S. C. (1997). Sympathetic burts activity: characteristics and significance. Cl. Exp. Pharmacol. Physiol. 24, 791-799.

MoruZZI, G. (1969). Sleep and instinctive behavior. Arch. Ital. Biol. 107, 175-216.

Mosqueda-Garcia, R., Furlan, R., TANK, J. \& FERnanDEZ-VIOLANTE, R. (2000). The elusive pathophysiology of neurally mediated syncope. Circulation 102, 2898-2906.

Nagashima, K., NaKai, S., Tanaka, M. \& Kanosue, K. (2000). Neural circuitries involved in thermoregulation. Auton. Neurosci. 85, 18-25.

Nicolis, G. \& Prigogine, I. (1977). Self-organization in nonequilibrium systems. New York: Wiley \& Sons.

NilsSON, S. (1983). Autonomic nerve function in the vertebrates. Berlin: Springer-Verlag.

OuREDniK, V., OUREDNiK, J., FlaX, J. D., ZaWAdA, W. M., Hutt, C., Yang, C., Park, K. I., Kim, S. E., Siddman, R. L., FREED, C. R. \& SNYDER, E. Y. (2001). Segregation of human neural stem cells in the developing primate forebrain. Science 293, 1820-1824.

OMODEO, P. (1983). The theory of the living being and evolution. Scientia 118, 51-64.

PARMEGgiani, P. L. (1988). Thermoregulation during sleep from the viewpoint of homeostasis. Clinical Physiology Sleep, (Lydic, R. \& Biebuyck, J. F., eds) pp. 159-169. Baltimore: American Physiological Society.
PAtTEE, H. H. (1987). Instabilities and information in biological self-organization. In: Self-Organizing Systems. The Emergence of Order (Yates, F. E., ed.), pp. 325-338. New York: Plenum Press.

PICK, J. (1970). The Autonomic Nervous System. Chapter 21, pp. 359-363. Philadelphia: JB Lippincott Co.

Pincus, D. W., DiCicco-Bloom, E. \& Black, I. B. (1992). Neuropeptide regulation of neuronal development. In: $D e-$ velopment, Regeneration and Plasticity of the Autonomic Nervous System (Hendry, I. A. \& Hill, C. E., eds), pp. 267-303. Switzerland: Harwood Academic Publishers. Prigogine, I. (1978). Time, structure and fluctuations. Science 201, 777-785.

Prigogine, I. \& Stengers, I. (1979). La Nuova Alleanza. Milano: Longanesi \& Co.

Prigogine, I. \& Stengers, I. (1984). Order out of Chaos-Man's New Dialog with Nature. New York: Bantam Books.

RECORDATI, G. (1984). The functional role of the visceral nervous system. A critical evaluation of Cannon's "Homeostatic" and "Emergency" theories. Arch. Ital. Biol. 122, 249-267.

RECORDATI, G. (1989). The visceral nervous system: homeostasis and the dissipative structure. International Union of Physiological Sciences, Satellite Symposium on: Central and Peripheral Interrelations between Blood Pressure Control Mechanisms, pp. 20-21, Abstract Book, Rostock/ GDR.

ReCordati, G. (1990). Determinismo, indeterminismo, omeostasi ed organizzazione funzionale del sistema nervosa viscerale. Cardiologia 35, 9-24.

ReCORDATI, G. (1999). The contribution of the giraffe to hemodynamic knowledge: a unified physical principle for the circulation. Cardiologia 44, 783-789.

ReCORdATI, G., LOMBARDi, F., Bishop, V. S. \& MALliani, A. (1976). Mechanical stimuli exciting type A atrial vagal receptors in the cat. Circ. Res. 38, 397-403.

Recordati, G., Moss, N. G., Genovesi, S. \& Rogenes, P. R. (1980). Renal receptors in the rat sensitive to chemical alterations of their environment. Circ. Res. 46, 395-405.

Recordati, G., Zorzoli, F. \& ZanchetTi, A. (2000). Effects of a reversible 'nephrectomy' on renal sympathetic activity and blood pressure in the rat: evidence for an acute angiotensin-mediated hypertension. J. Hypertens. 18, 1277-1287.

REINAGEL, P. (2001). The many faces of adaptation. Nature 412, 776-777.

Rockman, H. A., Koch, W. J. \& LefKowitz, R. J. (1997). Cardiac function in genetically engineered mice with altered adrenergic receptor signaling. Am. J. Physiol. 272, H1553-H1559.

SACK, R. L., Brandes, R. W., Kendall, A. R. \& LeWy, A. J. (2000). Entrainment of free-running circadian rhythms by melatonin in blind people. N. Engl. J. Med. 343, 1070-1077.

SAto, A., SATO, Y. \& SCHMidt, R. F. (1997). The impact of somatosensory input on autonomic functions. Rev. Physiol. Biochem. Pharmacol. 130, 1-328.

SEGAR, J. L. (1997). Ontogeny of the arterial and cardiopulmonary baroreflex during fetal and postnatal life. Am. J. Physiol. 273, R457-R471.

Sommers, V. K., DYKen, M. E., MARK, A. L. \& AbBoud, F. M. (1993). Sympathetic-nerve activity during sleep in normal subjects. N. Engl. J. Med. 328, 303-307. 
Spyer, M. (1999). Central nervous control of the cardiovascular system. In: Autonomic Failure (Mathias, C. J. \& Bannister, R., eds), 4th Edn, Chapter 6, pp. 45-55. Oxford: Oxford University Press.

SZE'KELY, M. (2000). The vagus nerve in thermoregulation and energy metabolism. Auton. Neurosci. 85, 26-38.

VACAs, M. I., Elverdin, J. C., Chiarenza, A. P. \& Luchelli, M. A. (2001). Daily changes in $\beta$-adrenergic sensitivity of rat submandibular gland. Correlation with $\beta$-adrenoceptor rhythm. Auton. Neurosci. 89, 1-6.

VON BERTALANNFy, L. (1971). Teoria generale dei sistemi. Milano: ISEDI (Original title: General System Theory, New York: G. Braziller).
YAtes, F. E. (1980). Physical causality and brain theories. Am. J. Physiol. 238, R277-R290.

YATES, F. E. (1987). Physics of self-organization. In: SelfOrganizing Systems. The Emergence of Order (Yates, F. E., ed.), pp. 409-416. New York: Plenum Press.

Young, J. B. \& LANDSBerG, L. (1977). Suppression of sympathetic nervous system during fasting. Science 196, 1473-1475.

ZANCHETTI, A. (1986). Volhard lecture: sympatho-renal interactions and blood pressure control. J. Hypertens. 4 (Suppl 6), S4-S13.

Zimmerman, B. G., Sybertz, E. J. \& Wong, P. C. (1984). Interaction between sympathetic and renin-angiotensin system. J. Hypertens. 2, 581-587. 